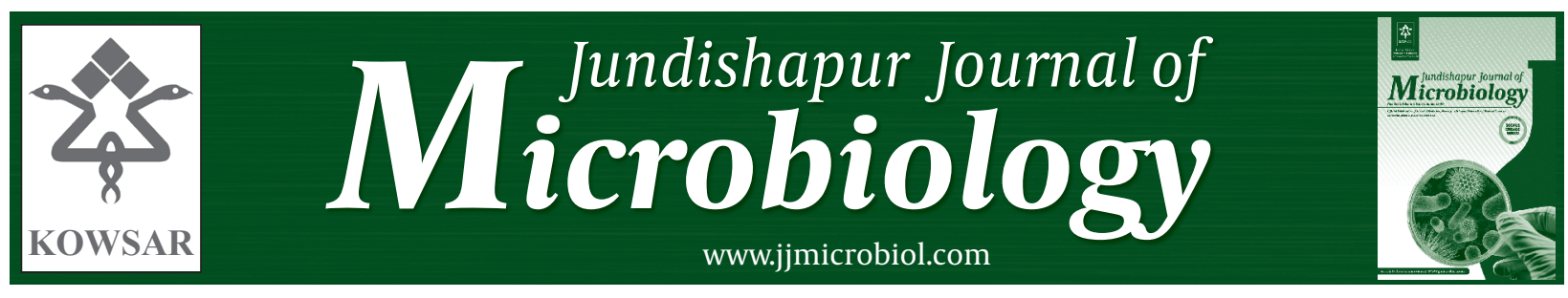

\title{
Study of Polyols Production by Yarrowia lipolytica in Batch Culture and Optimization of Growth Condition for Maximum Production
}

\author{
Gholam Reza Ghezelbash ${ }^{1 *}$, Iraj Nahvi ${ }^{1}$, Mohammad Rabbani ${ }^{1}$ \\ ${ }^{1}$ Department of Biology, Faculty of Science, University of Isfahan, Isfahan, IR Iran
}

\begin{tabular}{|c|c|}
\hline A R T I C L E I N F O & A B S T R A C T \\
\hline Article type: & Background: Sugar alcohol erythritol is a non-caloric sweetener, non-cariogenic, and \\
\hline Original Article & safe for diabetics because of no change to blood glucose and insulin levels after oral \\
\hline Article history: & eliminated from the blood through the kidney. \\
\hline Received: 13 Nov 2011 & Objectives: The aim of this study was production and optimization of erythritol from \\
\hline Revised: 6 Mar 2012 & glucose by Yarrowia lipolytica. \\
\hline Accepted: 6 Mar 2012 & Materials and Methods: $Y$. lipolytica DSM70562 was cultivated at $30^{\circ} \mathrm{C}$ in a $250 \mathrm{~mL}$ Er- \\
\hline Keywords: & yeast extract, $10 \mathrm{mg} / \mathrm{L}$ MnSO $.4 \mathrm{H}_{2} \mathrm{O}$, and $2 \mathrm{mg} / \mathrm{L}$ CuSO $4.5 \mathrm{H}_{2} \mathrm{O}$. Erythritol was separated \\
\hline Erythritol & from the sugars and other polyols by thin layer chromatography. Total polyols was de- \\
\hline Yarrowia lipolytica & termined using colorimetric method of Bok and Demain, and erythritol was also eluted \\
\hline Batch Culture & from the paper and determined by this colorimetric method. \\
\hline Optimization & Results: In a batch culture with $200 \mathrm{~g} / \mathrm{L}$ glucose at $\mathrm{pH}$ 5.5, an erythritol producer of $Y$. \\
\hline Polyols & lipolytica capable to produce $27.8 \mathrm{~g} /$ L erythritol after seven days was selected, correspond- \\
\hline & Conclusions: In this investigation we optimized the production medium and through \\
\hline & altering medium components that resulted in a drastic change in polyol composition. \\
\hline & Present study reports the production of erythritol for the first time by a Y. lipolytica strain \\
\hline & $\begin{array}{l}\text { DSM70562. Due to increasing demand for erythritol as a low caloric sweetener in food } \\
\text { industry, its production via biological processes is becoming increasingly important. }\end{array}$ \\
\hline
\end{tabular}

Published by Kowsar Corp, 2012. cc 3.0.

- Implication for health policy/practice/research/medical education:

Erythritol is one of the best low-calorie natural sweeteners. Unlike artificial sweeteners, erythritol does not have any significant side effects. In addition, erythritol does not raise plasma glucose or insulin levels.

Please cite this paper as:

Ghezelbash GR, Nahvi I, Rabbani M. Study of Polyols Production by Yarrowia lipolytica in Batch Culture and Optimization of Growth Condition for Maximum Production. Jundishapur J Microbiol. 2012;5(4):546-9. DOI: 10.5812/jjm.3524

\section{Background}

Polyols act as compatible solutes and can play a role in osmotic adjustment (1). Their role in membrane and protein protection is well established (2). The low molecular weight polyols, glycerol and erythritol, are more effective in osmotic adjustment than higher-molecular-weight compounds such as mannitol (3).

Erythritol is a four-carbon sugar alcohol with a molecular weight of 122. It is present in small quantities in fruits and fermented foods, $70-80 \%$ as sweet as sucrose with a

\footnotetext{
* Corresponding author: Gholam Reza Ghezelbash, Department of Biology, Faculty of Science, University of Isfahan, Isfahan, P.O. Box: 81746-73441, IR Iran. Tel: +983117932456; Fax:+98-3117932456; E-mail: gh.r.ghezelbash@gmail.com
}

DOI: $10.5812 / j j m .3524$

(C) 2012 Ahvaz Jundishapur University of Medical Sciences; Published by Kowsar Corp.

This is an Open Access article distributed under the terms of the Creative Commons Attribution License (http://creativecommons.org/licenses/by/3.0), which permits unrestricted use, distribution, and reproduction in any medium, provided the original work is properly cited. 
very low caloric value of 0.2 calories per gram. This noncaloric sweetener is an important sugar alcohol being industrially produced only by fermentation $(4,5)$. Industrial production of erythritol began in Japan in 1990 and has been used as sugar substitutes for candies, chocolates, soft drinks, chewing gum, jellies, jams and yogurt. It has been approved in U.S.A. in 2001 and used as a flavor enhancer, formulation aid, humectant, nutritive sweetener, stabilizer, thickener, sequestrant and texturizer at maximum levels of $100 \%$ in sugar substitutes (6).

Erythritol can be produced by osmophilic yeasts belonging to the genus Aureobasidium, Candida, Moniliella, Pichia, Pseudozyma, Trigonopsis, Trichosporon, Trichosporonoides and Yarrowia (5). Industrially, erythritol has been produced by the use of a mutant of Aureobasidium sp. at a rate of $1.81 \mathrm{~g} / \mathrm{L} / \mathrm{h}$ with a high yield of $44 \%$ in a medium containing 40\% glucose (7-9).Y. lipolytica has been reported to produce several polyols and organic acids such as erythritol, glycerol and citric acid. The composition of polyols produced by Y. lipolytica depends on the nature, composition and concentration of media constituents. The objective of the present study was to improve polyols production from Y. lipolytica by optimization growth condition in batch culture to minimize formation of glycerol. In addition, the erythritol production of the strain was improved with the range of glucose in batch culture.

\section{Objectives}

The aim of this study was erythritol production by Y. lipolytica. This study is the first research for erythritol production in Iran.

\section{Materials and Methods}

\subsection{Microorganisms and Media}

Y. lipolytica DSM70562 was obtained from DSMZ collection culture. The growth medium for activation contained 100 $\mathrm{g} / \mathrm{L}$ glucose and $10 \mathrm{~g} / \mathrm{L}$ yeast extract. Yeast cultures maintained at $4^{\circ} \mathrm{C}$ and sub-cultured each 4 weeks. The production medium contained $200 \mathrm{~g} / \mathrm{L}$ glucose, $10 \mathrm{~g} / \mathrm{L}$ yeast extract, 10 $\mathrm{mg} / \mathrm{L} \mathrm{MnSO}_{4} \cdot 4 \mathrm{H}_{2} \mathrm{O}$, and $2 \mathrm{mg} / \mathrm{L} \mathrm{CuSO}_{4} \cdot 5 \mathrm{H}_{2} \mathrm{O}$ in flask culture.

\subsection{Culture Conditions}

A single colony Y. lipolytica was inoculated into a $100 \mathrm{~mL}$ Erlenmeyer flask containing $10 \mathrm{~mL}$ of production medium and incubated at $30^{\circ} \mathrm{C}, 180 \mathrm{rpm}$ for $48 \mathrm{~h}$. Two and half milliliters of the broth was transferred into a $250 \mathrm{~mL}$ Erlenmeyer flask containing $50 \mathrm{~mL}$ production medium and incubated at $30^{\circ} \mathrm{C}$ for seven days on a reciprocating shaker with 180 rpm. Initial $\mathrm{pH}$ of the production medium was adjusted at $5.5(4,10)$. Fermentation samples were run and analyses usually were performed at $24 \mathrm{~h}$ intervals or when the fermentation was judged as complete. Samples were analyzed for residual sugar, total polyol concentration, erythritol concentration, and biomass density.

\subsection{Optimization of Erythritol Production}

Effects of environmental factors on erythritol production were studied. The process was examined in the presence of various carbon sources as well as nitrogen source, temperature, and initial $\mathrm{pH}$.

\subsection{Choice of Carbon Source}

To study the effect of carbon sources on erythritol production by Y. lipolytica, glucose from production medium was substituted by sucrose at the concentration of 100 $\mathrm{g} / \mathrm{L}$. Respective media were inoculated with two and half milliliters of seed cultures from the activated culture and incubated at $30^{\circ} \mathrm{C}, 180 \mathrm{rpm}$ on rotary shaker. After one week, samples were analyzed for biomass, residual glucose, and polyol concentration.

\subsection{Effect of Yeast Extract}

The effect of the yeast extract concentration on erythritol production in production medium was examined by $20 \%$ glucose as a carbon source. Two and half milliliters of seed cultures were inoculated in $250 \mathrm{~mL}$ Erlenmeyer flasks with $50 \mathrm{~mL}$ medium of varying yeast extract concentrations ranging from 0.5 to $2.5 \%$ and incubated at $30^{\circ} \mathrm{C}, 180 \mathrm{rpm}$ for seven days. Samples were analyzed as described earlier.

\subsection{Effect of Initial $p H$}

Effect of initial pH on erythritol production was studied in shake flasks with $50 \mathrm{~mL}$ production medium. The $\mathrm{pH}$ of a production medium plays a vital role in the production of various products. In this experiment a range of $\mathrm{pH}$ from 4 to 7 was studied and used for final production. Incubation temperature of fermentation medium was maintained at $30^{\circ} \mathrm{C}$.

\subsection{Analytical Methods}

Yeast growth was measured by centrifuging a sample of the fermented liquor, washing the yeast twice with distilled water, and drying at $80{ }^{\circ} \mathrm{C}$ in $12 \mathrm{~h}$. Glucose was measured using dinitrosalicylic acid method (9) after cell removal by centrifugation. The supernatant liquid from the yeast centrifugation was used for further analyses. Erythritol was separated from the sugars and other polyols by thin layer chromatography (TLC). TLC was conducted using a solvent system composed of ethyl acetate: 2-butanol: water in the ratio of 6:3:1 by volume. Polyols were stained and detected by spraying $1 \% \mathrm{NaIO}_{4}$ on the samples followed by $1 \% \mathrm{KMnO}_{4}$ (11). Polyols create yellow spots on purple background. Total polyols were determined by colorimetric method of Bok and Demain (12); the same method was applied to elute and determine erythritol from the paper. Yield of erythritol production was calculated by this formula: yield $(\%)=($ erythritol $/$ carbon source consumption) $\times 100 \%$. 


\section{Results}

4.1. Optimization of Polyols Production (Choice of Carbon Source)

Figure 1 shows a sample of TLC which stained by $1 \% \mathrm{NaIO}_{4}$ and $1 \% \mathrm{KMnO}_{4}$. This strain produces maximum amount of erythritol after seven days (Figure 2). Despite of sucrose and lactose, glucose showed to keep organism growing and producing erythritol well. Glucose at concentration of $20 \%$ revealed maximum production and yields (Figure.3).

Figure 1. Separation of Polyols by TLC

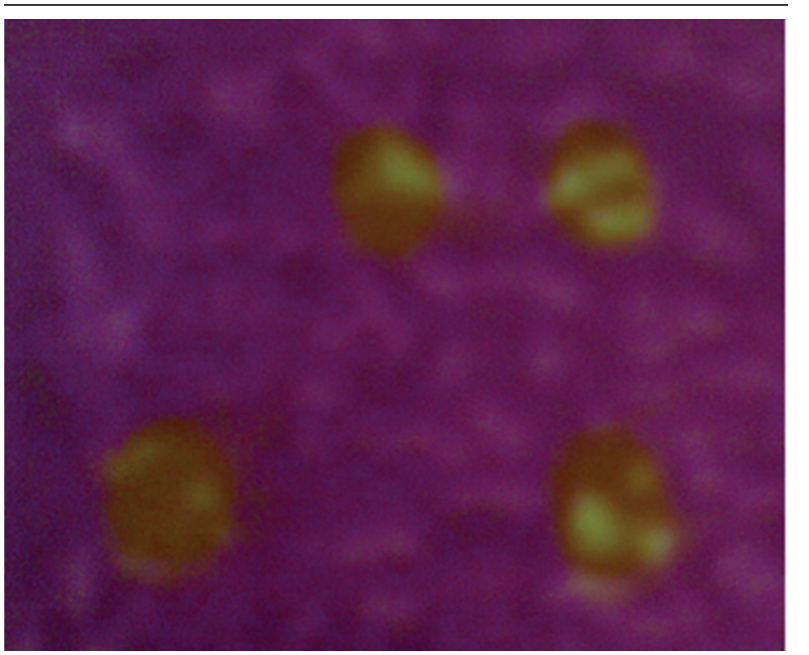

1

Lane 1: Erythritol; Lane 2: Glycerol; Lane 3: Products of Y. lipolytica DSM70562 in Fermentation Medium

Figure 2. Glucose Consumption and Cell Growth During Polyol Production by Y. lipolytica

$\leftrightharpoons$ Polyol $\cdots$... Sugar Residue $\quad \longrightarrow \rightarrow$ Biomass

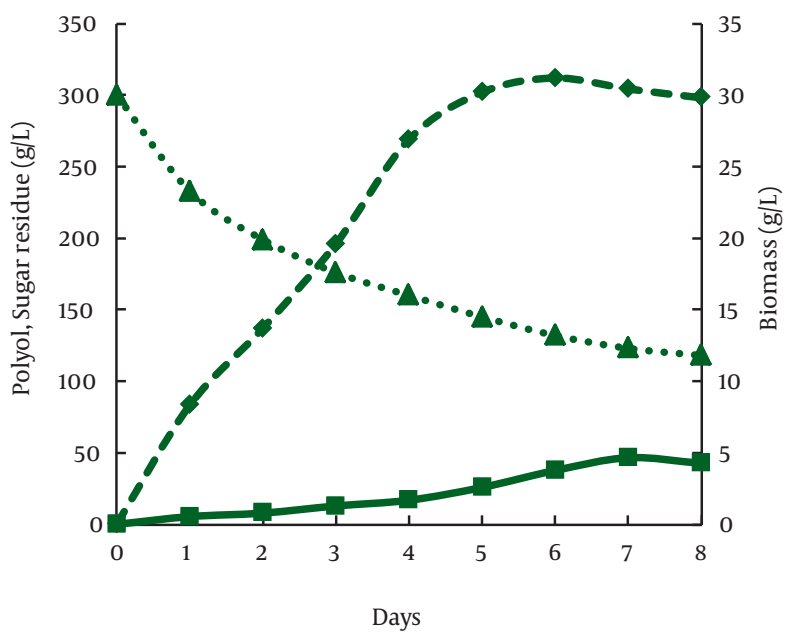

(๘) Polyol, ( $\mathbf{\Delta})$ sugar residue, ( $\bullet$ Biomass (dry weight)

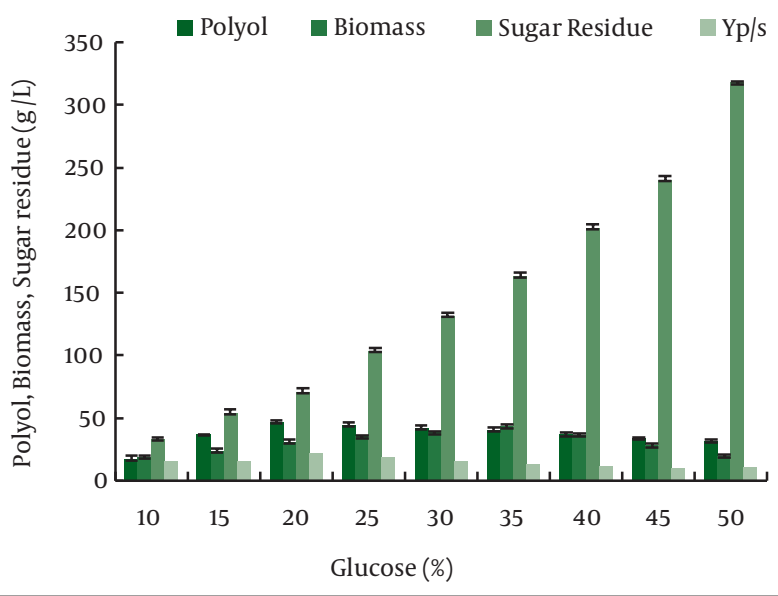

Figure 3. Effects of Concentration of Glucose on Polyol Production

\subsection{Effect on Yeast Extract}

Yeast extract concentrations varied from 0.5 to 2.5 $\%$. At the highest level of yeast extract concentration, yeast growth was excessive and polyols yields were very low. Figure 4 shows that $1.0 \%$ of yeast extract is the best amount of this source for polyols production. TLC also showed that $1.0 \%$ of yeast extract is the best concentration for erythritol production. Based on sugar consumed, at the lowest level of yeast extract concentration, erythritol yields, appeared well, however sugar utilization was very slow as a result of low cell concentrations.

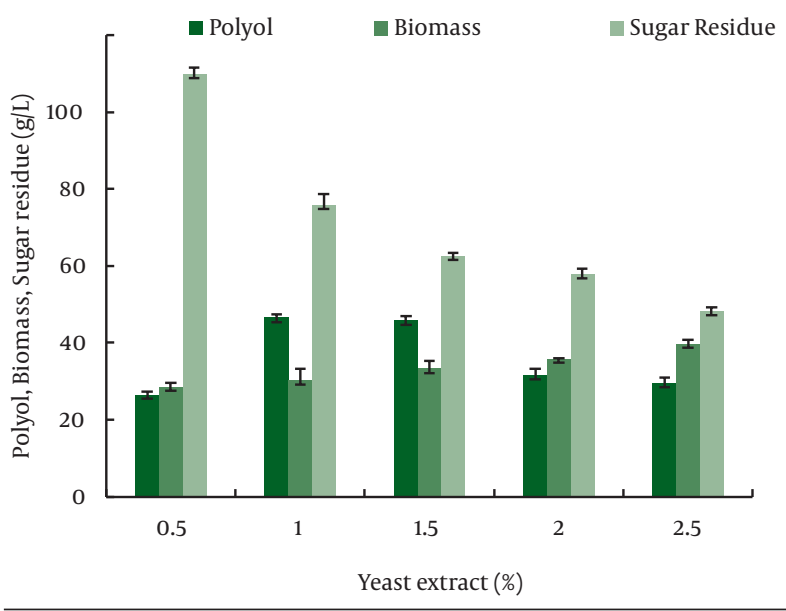

Figure 4. Effects of Concentration of Yeast Extract on Polyol Production

\subsection{Effect of Initial $p H$}

Yarrowia grows in a broad spectrum of $\mathrm{pH}$ but the highest amount of polyols production occurred at $\mathrm{pH} 5.5$ (Figure. 5) and detected by TLC; an alkaline $\mathrm{pH}$ led to an increase in glycerol production. 


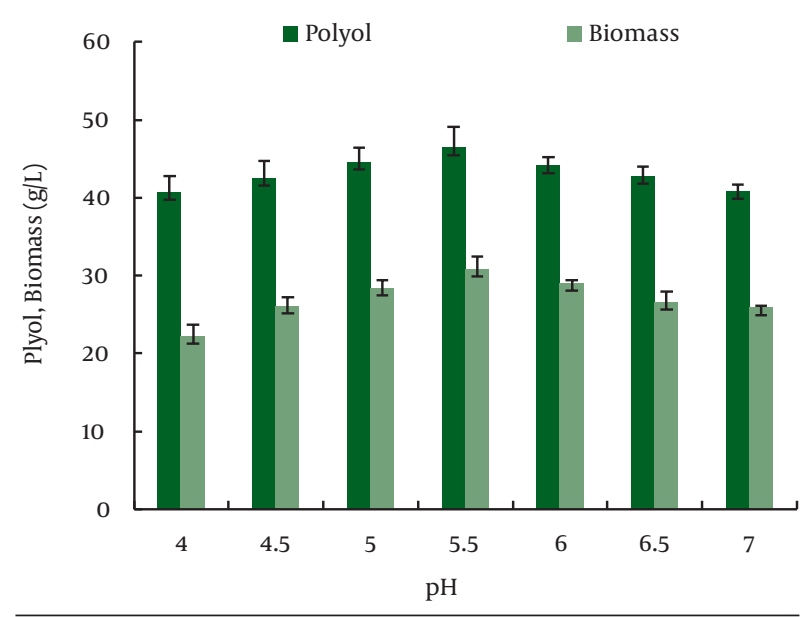

Figure 5. Optimal pH for Production of Polyol

\section{Discussion}

The concentration and pattern of polyols produced by osmotolerant yeasts are strongly influenced by medium composition and environmental conditions (10). The pathways for polyols biosynthesis and catabolism can be different among organisms (11). It was observed that $Y$. lipolytica produced $60 \%$ erythritol out of total produced polyols. The preliminary screening experiments (one-factor at a time) suggested that glucose - as carbon source - and yeast extract - as nitrogen source - were critical medium components for erythritol formation. Pattern of polyol production can be drastically altered by changing the medium components $(10,13)$.

In this study characterized that at concentration higher than $1.0 \%$ of yeast extract, glycerol production rate was much higher than that of erythritol. These results indicate that the addition of yeast extract facilitated and enhanced glycerol production. Alkaline $\mathrm{pH}$ led to an increase in glycerol production. The optimum $\mathrm{pH}$ for erythritol production was determined to be 5.5which was almost the same as optimum $\mathrm{pH}$ ( $\mathrm{pH}$ 5.6) for Aureobasidium sp. reported by Wako et al. (14). Erythritol is commercially produced by fermentation of Aureobasidium sp., Torula sp., and Moniliella pollinis (5). Erythritol production by $Y$. lipolytica DSM70562 needs gene engineering such as overexpression of erythrose reductase, and deletion or decrease of glycerol production by ultraviolet irradiation.

\section{Acknowledgements}

The current study was supported by the grant of Postgraduate Administration Office of the University of Isfahan to Gh. R. Ghezelbash for obtaining Ph.D. degree

\section{Financial Disclosure}

None declared.

\section{Funding Support}

None declared.

\section{References}

1. Hallsworth JE, Magan N. Culture Age, Temperature, and pH Affect the Polyol and Trehalose Contents of Fungal Propagules. Appl Environ Microbiol. 1996;62 (7):2435-42.

2. Carpenter JF, Crowe JH. Modes of stabilization of a protein by organic solutes during desiccation. Cryobiology. 1988;25 (5):459-70.

3. Chirife J, Favetto G, Ferro Fontan C. Microbial growth at reduced water activities: some physicochemical properties of compatible solutes. J Appl Bacteriol. 1984;56 (2):259-68.

4. Kim KA, Noh BS, Lee JK, Kim SY, Park YC, Oh DK. Optimization of culture conditions for erythritol production by Torula sp.J Microbiol Biotechnol. 2000;10 (1):69-74.

5. Moon HJ, Jeya M, Kim IW, Lee JK. Biotechnological production of erythritol and its applications. Appl Microbiol Biotechnol. 2010;86 (4):1017-25.

6. Park YC, Lee DY, Lee DH, Kim HJ, Ryu YW, Seo JH. Proteomics and physiology of erythritol-producing strains. J Chromatogr B Analyt Technol Biomed Life Sci. 2005;815 (1-2):251-60.

7. Ishizuka H, Wako K, Kasumi T, Sasaki T. Breeding of a mutant of Aureobasidium sp. with high erythritol production. J Ferment Bioeng. 1989;68 (5):310-4.

8. Lee JK, Ha SJ, Kim SY, Oh DK. Increased erythritol production in Torula sp. by $\mathrm{Mn}^{2+}$ and $\mathrm{Cu}^{2+}$. Biotechnol Lett. 2000;22 (12):983-6.

9. Miller GL. Use of dinitrosalicylic acid reagent for determination of reducing sugar. Anal Chem. 1959;31 (3):426-8.

10. Yang SW, Park JB, Soo Han N, Ryu YW, Seo JH. Production of erythritol from glucose by an osmophilic mutant of Candida magnoliae. Biotechnol Lett. 1999;21 (10):887-90.

11. Lee KJ, Lim JY. Optimized conditions for high erythritol production by Penicillium sp. KJ-UV29, mutant of Penicillium sp. KJ81. Biotechnol Bioprocess Eng. 2003;8 (3):173-8.

12. Bok SH, Demain AL. An improved colorimetric assay for polyols. Anal Biochem. 1977;81 (1):18-20.

13. Savergave LS, Gadre RV, Narayanan BK. Strain improvement and statistical media optimization for enhanced erythritol production with minimal by-products from Candida magnoliae mutant R23. Biochem EngJ. 2011;55 (2):92-100.

14. Wako K, Ishizuka H, Kawaguchi G, Kubo N, Kasumi T, Hayashi K. Erythritol production by Aureobasidium sp. SN-115. J Ferment Technol.1988;66 (4):479-83. 